\title{
Birth and Expansion of Innovation Ecosystems:A Case Study of Copper Production
}

\author{
Ozgur Dedehayir', Marko Seppänen²
}

\begin{abstract}
Despite the growing attention innovation ecosystems have received from scholars and practitioners, rather little is known about the crucial birth and expansion phases that these ecosystems experience. Through a single case in the complex product system (CoPS) environment, this paper investigates the development of an innovation ecosystem between 1980 and 2007. The findings demonstrate that the ecosystem's birth phase includes sub-phases, namely, invention and start-up, where the ecosystem is reconfigured to find the appropriate form and the proper actors to satisfy the first customer's requirements. Moreover, the duration of the expansion phase is found to be remarkably long, suggesting that within the CoPS setting, expansion may also include two or more sub-phases.
\end{abstract}

Keywords: innovation ecosystem; life cycle; complex product system; copper production.*

\footnotetext{
'School of Management, Queensland University of Technology, Level 9, Z Block, 2 George Street, Brisbane 4000, QLD, Australia. Phone: +6I 73138 2050. e-mail: ozgur.dedehayir@qut.edu.au ${ }^{2}$ Department of Pori, Tampere University of Technology, P.O. Box 300, Fl-28I0I Pori, Finland. Phone: +358 405884080. e-mail: marko.seppanen@tut.fi

* An earlier version of this research has been presented at the International ICE Conference on Engineering, Technology and Innovation, The Hague, The Netherlands, 24 - 26 June, 2013.
}

ISSN: 07 I8-2724. (http://www.jotmi.org) 


\section{Introduction}

The systemic nature of products and services bring together specialized firms from different industries into an integrated organizational system or network. Referred to as business ecosystems or innovation ecosystems, this network of organizations aim to deliver holistic product or service value to the end-user. The semiconductor lithography ecosystem (Adner and Kapoor, 2010), the PC (personal computer) ecosystem (Cusumano and Gawer, 2002), and the Firefox browser ecosystem (Tiwana et al., 2010) are just some examples of such organizational networks that sponsor collective and interdependent innovation.

The burgeoning significance of ecosystems thinking for both practitioners and scholars has culminated in different research agendas, which aim to enhance our understanding of what innovation ecosystems are and how they change over time (Mäkinen and Dedehayir, 20I2).Adner (20I2) gives a prominent example of this by introducing methods for designing the ecosystem's 'value blueprint' (i.e. locations and links between ecosystem actors), foreseeing risks to value creation, determining the value of leadership and followership roles in the ecosystem, timing of innovation introductions, and the dynamic reconfiguration of the ecosystem over time. Notwithstanding this and similar valuable contributions, the process of how ecosystems come to existence in the first place has received scarce attention. In this paper, we aim to address this very issue. Using the ecosystem life cycle phases (birth, expansion, leadership, and self-renewal) identified by James F. Moore (1993), a pioneering scholar in this field of inquiry, we pose the following research question: how are innovation ecosystem born and how do they expand?

Our paper commences with a short review of the ecosystems literature focusing on the actors that constitute these networks, and an elaboration of the life cycle phases of ecosystem change. We then employ a case study methodology, given the nature of the research question that is posed, to explore the actors, their actions, and other events that mark the birth and expansion of a single innovation ecosystem. The empirical case we analyze is the 'flash converting furnace' ecosystem, which represents the network of organizations that collaborate in producing the complex product system (i.e. the furnace) integrated into copper smelting operations. Our case study results underline seminal factors, such as ecosystem leadership, key actors, and external influences, which govern the evolution of the ecosystem from the initial discovery of the technology until the successful commercialization of the technology in different application areas.

\section{Theoretical Background Ecosystem actors}

Innovation ecosystems describe the network of firms, which collectively produce a holistic, integrated product system that creates value for firms as well as end-users. The ecosystem comprises a number of organizations, which can be classified under some generic types. The most significant member of an ecosystem is the 'keystone' (lansiti and Levien, 2004), also referred to as platform leader (Cusumano and Gawer, 2002) or ecosystem leader (Moore, 1993), which regulates the overall function of the ecosystem. Even though keystones exert substantial power within a given ecosystem and command a greater share of the overall profits (Moore, 1993), they represent only a small biomass or population of organizations of that ecosystem (lansiti and Levien, 2004). For example, firms such as Wal-Mart, Microsoft, Apple, and Mozilla have been crucial platform leaders to their respective ecosystems.

The keystone is supported by 'niche players', which form the great majority of the ecosystem and generate the largest portion of innovations as well as the created value. Niche players have specialized functions that contribute toward the holistic function of the ecosystem. Their specialization also helps them differentiate from other members of the ecosystem. The role of niche players in the ecosystem often means that they are also 'complementors' who help the platform leader expand the realms of its application. For example, Intel and Microsoft are platform leaders in the PC ecosystem because they assume great authority in the architectural design of the PC system and subsequently govern a plethora of complementors (i.e. firms offering complementary technologies), which produce platform-specific hardware and software products (Cusumano and Gawer, 2002). 


\section{Ecosystem life cycle}

Moore (1993) suggests that innovation ecosystems progress through four life cycle phases: birth, expansion, leadership, and self-renewal (or death). Each phase is marked by certain characteristics, which we elaborate below.

In the birth phase the product and service requirements of the customer must be well understood by all members of the ecosystem. This understanding guarantees the collaboration of actors towards common objectives. In this phase, the ecosystem leader assumes a central position by securing the cooperation of key organizations which will provide complementary products and services that will collectively deliver value to the customer. It is also important for the keystone to protect the new innovation idea from competitors, while at the same time forging strong ties with lead customers and important channels of delivery (Moore, 1993).

In the second phase, the ecosystem expands into new territories of application. It is possible that rivalries eventuate as the same application realm may be targeted by different ecosystems. These battles are more likely to be won by a given ecosystem if established organizations apply their expertise in complementary assets, such as marketing and sales, as well as production and distribution, to the ecosystem's cause. Expansion into new territories naturally requires the stimulation of market demand albeit within the capacity of the ecosystem. It is therefore vital that the ecosystem leader is able to maintain strong relationships with the customer and at the same time with suppliers (Moore, 1993).

The third stage of ecosystem evolution is a period of consolidation and establishment. This stage centers on establishing ecosystem leadership and the establishment of stability in the ecosystem's sub-systems and processes. These foundations, together with a clear vision of future development, enhance the commitment of component suppliers and complement producers, thereby institutionalizing a true network of cooperators (Moore, 1993). And the final stage is a response of the mature ecosystem to emerging threats from new ecosystems and innovations, or significant upheavals and alterations in the ecosystem's environment, such as those pertaining to government regulations and demographic traits, which create opportunities for new ecosystems to emerge. There are two possible reactions to these challenges: self-renewal or death of the ecosystem.

\section{Method}

We employ the case study methodology in our empirical work, as our objective is to investigate the birth and expansion of a contemporary innovation ecosystem, and furthermore, because it is a preferred approach for the form of research question that we have raised (Yin, 1994). Following the general guideline stipulated by $Y$ in (1994), we implemented a single, holistic case study design, and collected and analyzed data through different case related sources.

In accordance with our research question, the innovation ecosystem was chosen as the unit of analysis. The selected case manifests the innovation ecosystem intensely, but not extremely (Miles and Huberman, 1994) - it represents a typical technological invention in the industrial settings where the time scale is a quarter of a century. We studied the 'Flash Converting Furnace' (FCF) innovation ecosystem, which centers about a complex product system (Miller et al., 1995) used in copper production. In our case study we investigated the actors that played central roles and the events that took place during the birth and expansion of the ecosystem, from the time of first discovery of a technology that carried commercialization potential (i.e. 198I-82) until the present. The evidence accessed in our case study was sourced primarily from interviews, and supplemented by documents.

We conducted two rounds of interviews with key informants from the keystone organization, Outotec, of the FCF ecosystem . In the first round, our aim was to access information on the innovation itself and its impact on the copper production industry. By reviewing the results of the first round of interviews, we were able to hone the focus of the follow up interview on the ecosystem birth and expansion. All interviews were kept open-ended, with a focus on guiding the conversation rather than maintaining a strict query structure. The duration of the interviews ranged between two and three hours, with some flexibility implemented to cater for the open-ended nature of the interview. An external analyst then transcribed the audio recordings of the interviews, and the investigators scoured the transcript records in a systematic fashion to reveal vital information. This information was, in turn, compared to the notes and observations produced during the interviews. In this manner, we performed triangulation among different evaluators (Yin, 1994). 


\section{Findings:The FCF innovation ecosystem}

The copper extraction process begins with mining of copper ore, which contains only a very small percentage of copper. Successive processes separate the copper from the rock and other valueless materials that surround it. These sequential steps include comminution (reducing the mined solid materials in size, e.g. through crushing), froth flotation (processing the crushed ore to produce copper concentrate), and roasting (partially oxidizing the concentrate for further treatment). However, in recent decades this roasting step has been made redundant with the adoption of the flash smelting technique, which is a high temperature process that produces liquid in the form of copper matte (containing copper in the form of copper and iron sulfides) and slag (unwanted metal and silicon oxides). The flash converting process (using the FCF), in turn, treats the copper matte by removing the iron and sulfur, leaving behind almost pure copper (Schlesinger et al., 20I I).

The FCF can be classified as a complex product system (CoPS) because of its inherent complexity that brings together knowledge from a wide range of scientific realms, including "flash reactions, slag chemistry, flow phenomena in the furnace, and the process thermodynamics" (Kojo et al., 2009), its low gas volume production, its B2B nature coupled with relatively high unit costs, and its long life cycle that spans decades. The FCF is a sub-system of the copper smelting facility, and has been first commercialized by Outotec (former technology division of Outokumpu) and Kennecott. Outotec also acts as the system integrator that supplies the core, proprietary technologies of the flash converting furnace, while integrating technologies produced by a number of suppliers.

\section{Ecosystem birth}

The birth of the FCF innovation ecosystem began in 198182, with the invention of the Solid Matte Oxygen Converting (SMOC) technique. The inventor, an employee of the copper smelting firm Kennecott Utah Copper (Salt Lake City, Utah, USA), contacted Outotec with the possibility of developing a copper conversion process based on his discovery, thereby initiating the formation of the ecosystem. The connection between the inventor and the soon-to-be keystone organization, Outotec, triggered a series of search routines within the latter to verify the technical viability of converting copper using SMOC. References were known for comparable technological applications, such as in already existing Australian and Polish copper smelting facilities, and Outotec's own research center was engaged with the task of conducting research into technical issues. These

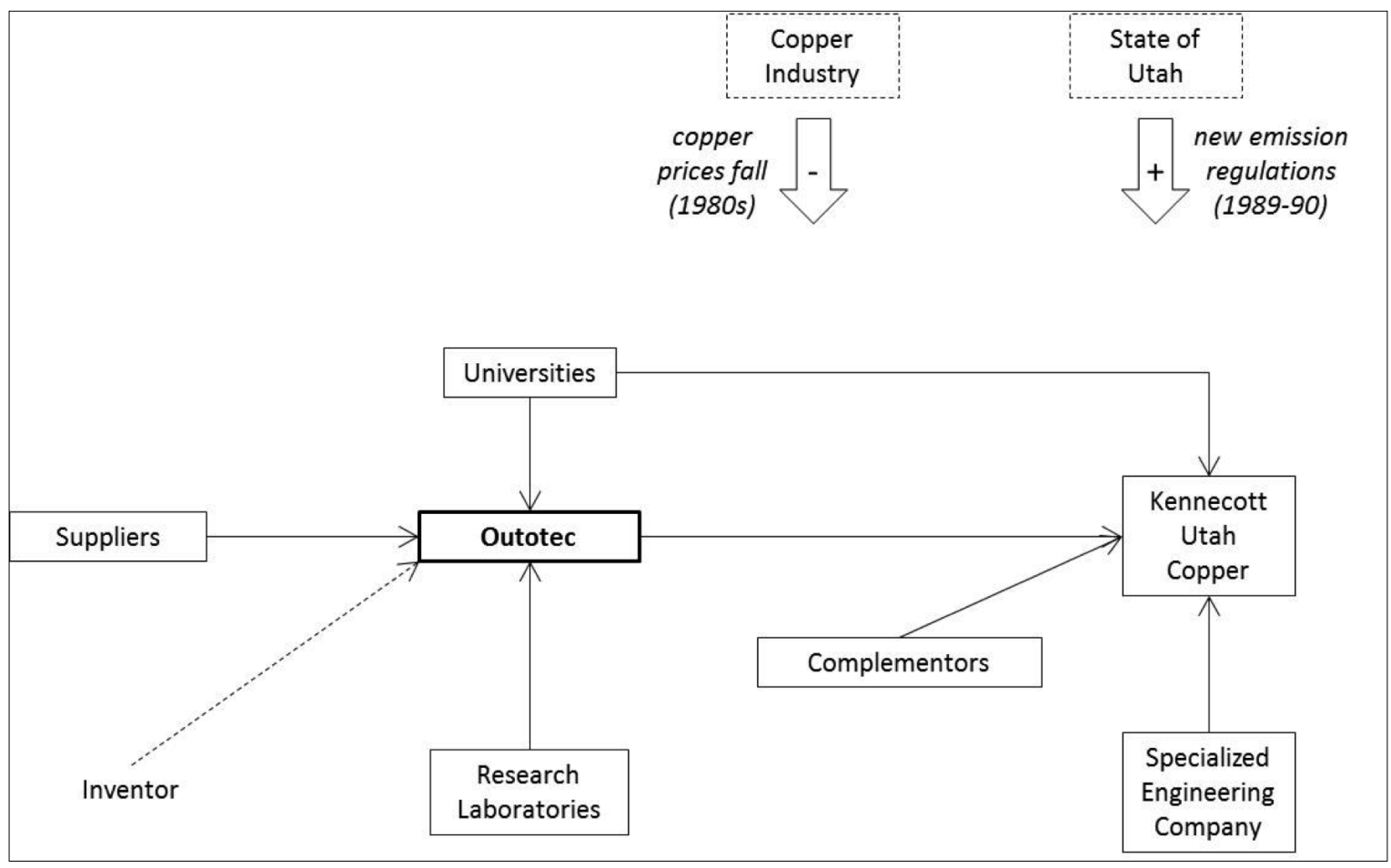

Figure I.The FCF innovation ecosystem at birth.

ISSN: 07I 8-2724. (http://www.jotmi.org) 
technical feasibility studies were followed by two pilot tests conducted in Outotec's research center (Pori, Finland), in 1984 and 1985, respectively.

The four year period from initial discovery of the SMOC technique to pilot testing of the FCF technology had already brought and linked ecosystem actors such as Outotec (the ecosystem leader), the suppliers of sub-system technologies integrated into the FCF by Outotec, research laboratories, and a (potential) direct customer in Kennecott Utah Copper. Additionally, the complementors that entered the fray leading up to pilot testing were the providers of technological subsystems integrated into Kennecott's smelting facility to function together with the FCF, and also the universities. Columbia University developed numerical models for the flash converting process, while the Helsinki University of Technology and the University of Utah provided support to both Outotec and Kennecott through basic research and kinetic models. These actors and their connections during the birth phase of the FCF innovation ecosystem are shown in Figure I.

In the 1980's, however, the copper industry was hit with a substantial fall in copper prices, which led to a four year delay in Kennecott's implementation of the FCF technology (Figure I marks this as a negative external influence to the evolution of the ecosystem). It was not until the end of the 1980s and the very beginning of the 1990s that Kennecott reinitiated efforts to integrate the FCF technology into their facilities. The recommencement of this effort was aided by yet another factor external to the ecosystem, when the State of Utah introduced new emission regulations in 1989-90, thus encouraging, perhaps better still, compelling production plants to align with the new levels of allowed emissions (Figure I marks this as a positive external influence to the evolution of the ecosystem).Among others, this was a factor that brought the FCF technology back onto the table of Kennecott executives.

During this time, the center of gravity in the ecosystem's development seemed to have shifted from Outotec in Finland to Kennecott in the USA. Our case study also shows that Kennecott linked a new actor to the ecosystem in the form of a specialized engineering company to assist in exploring technological options, and simultaneously played a major role in coordinating the final large-scale implementation of the FCF technology. This nevertheless should not come as a surprise, given that Kennecott would need to bear the consequences of a large investment in the form of benefits as well as risks that would emerge from integrating the technology into their production line. After the final largescale testing in 1991 (conducted at the Pori pilot plant with solidified matte produced at the Harjavalta smelter in Finland), Kennecott integrated the FCF technology into the modernized Utah plant. In 1995, the first Flash Converting Furnace was put into operation at Kennecott Utah Copper. The implementation of the FCF technology at Kennecott's copper smelting facility was accompanied by technical problems, which limited the operational capacity of the technology. While these problems did not originate from within the technical scope of the FCF technology itself, the systemic nature of the copper smelting operation meant that insufficient capacity in complementary technologies acted as bottlenecks to copper conversion through the FCF. For example, capacity deficiency was observed in the anode casting sub-system. This bottleneck was resolved by subtracting the original sub-system provider from the ecosystem and awarding the anode casting contract to Outotec's engineering division. By 1996-97, in other words approximately two years after the first implementation of the FCF technology, the technical bottlenecks were alleviated, allowing the FCF technology to deliver its designed operational capacity in the field. This date therefore marks the time of first successful commercial application of the technology, and as a result ends the birth phase of the ecosystem.

\section{Ecosystem expansion}

Having commercialized the FCF technology, Outotec directed the innovation ecosystem to the phase of expansion. In the case of the FCF innovation ecosystem, expansion meant implementing the technology in different copper smelting plants, possibly entailing different geographical contexts. To this end, the ecosystem first recognized an opportunity to expand within Finland, the home turf of the keystone organization, where the Harjavalta smelter (Outokumpu's base metals division, earlier involved in pilot testing) was planning to increase production capacity in 1995-96. The possibility of increasing plant capacity using old copper converting technology released from another production unit (which would also reduce costs), placed the proponents of the FCF technology in opposition with those in favor of the older technology. This internal dialogue nonetheless rejected FCF implementation, thereby closing the first opportunity for ecosystem expansion.

However, there were more than 150 copper smelters in operation around the world in the early 2000s , and between 1999 and 2002, the ecosystem sought expansion into the South American application field, a region that is globally prominent in copper production. Nevertheless, the opportunities successively dissipated here as well. In Peru, the Southern Peru Copper Corporation (SPCC) initiated a project to expand production capacity, while concurrently reducing emissions. They turned to Outotec for the FCF technology, which would enable the smelter to attain its objectives. Despite carrying out small-scale pilot 
tests, however, FCFs were not integrated into the Peruvian smelter for two reasons outside of the keystone's direct control. Firstly, the new emission regulations in Peru were in fact not as stringent as they were back in Europe or the U.S. The emission reduction objective of SPCC thus appeared to be self-motivated. Secondly, when a Mexican copper company acquired substantial shares of SPCC, the void between actual regulations and SPCC's emission reduction initiative was exploited, resulting in the smelter being rebuilt without FCFs. The first South American expansion effort was subsequently unsuccessful. Two other attempts were made, this time in Chile, where new copper smelters were planned to be built. While Outotec joined these plans with the possibility of integrating FCFs, these projects were only later to be cancelled. These unsuccessful ecosystem expansion endeavors are shown in Figure 2.
After these unsuccessful expansion attempts, the FCF innovation ecosystem was finally able to expand into the Chinese market in 2007 (see Figure 2). The opportunity for expansion into this area (yet another prominent copper producing region) was already created in 1997 when the Chinese Central Government brought in new regulations for emissions. Over the following years, these regulations were tightened by both the Central Government and the Chinese Local Governments. Within this newly regulated context, Outotec was approached by a Chinese entrepreneur in 2005, who showed great interest in investing in a new copper smelter. Only two years later, in 2007, the FCFs were implemented in the new (i.e. greenfield) Yanggu Xiangguang Copper smelter (Kojo et al., 2009). Even more significantly, the new smelter also served as an exemplar for other

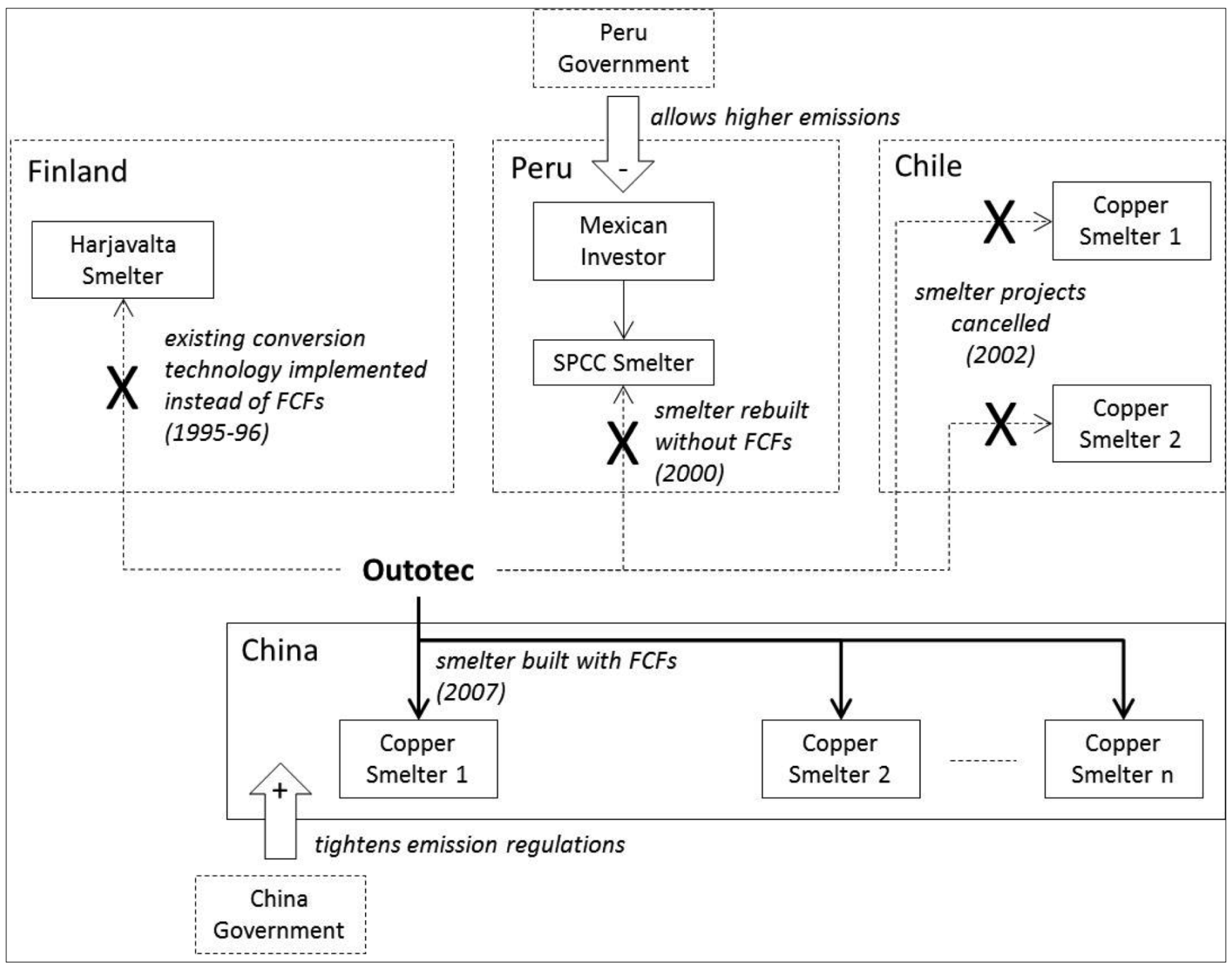

Figure 2. The FCF innovation ecosystem at expansion.

ISSN: 07I 8-2724. (http://www.jotmi.org) 
Chinese copper smelters, which, under the tighter emission regulations, opted to increase their own production capacities with FCFs. Consequently, after approximately 12 years, the expansion phase of the FCF innovation ecosystem had commenced in 2007.

\section{Discussion}

The birth phase of the ecosystem life cycle spans the time from the discovery of a new technology until the first successful commercialization of that technology. Our case study shows that the birth phase can be divided into two distinct sub-phases, namely, the 'invention' and the 'start-up' sub-phases as shown in Figure 3.

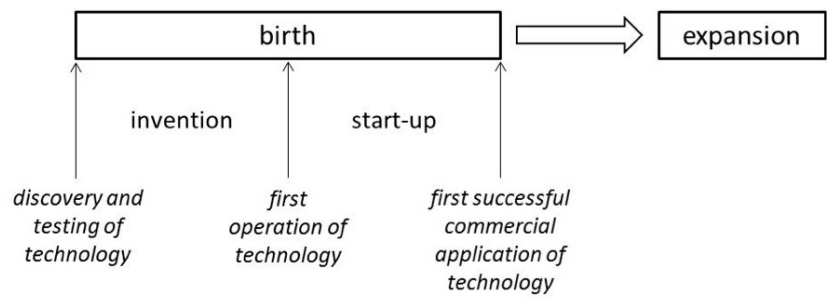

Figure 3. The birth and expansion phases of ecosystem life cycle.

The invention sub-phase marks the discovery of a new technique, method, product, or process, in other words a new technology, and also incorporates the technical feasibility assessment of the technology (e.g. through pilot testing). The discovery of a new technology is at times the result of systematic exploration and at other times through mere serendipity. This period of ecosystem development importantly relies on the roles of individuals, such as scientists and engineers who discover, manipulate, and work towards the application of the technology, laying the first stones on the pathway towards technology commercialization. The seminal role of individuals is an important observation and valuable addition to the existing model of ecosystem development, which predominantly considers the actors at the organizational level.

The work of individuals in the invention sub-phase is supported by other actors such as universities and research laboratories, which provide scientific support and establish technical feasibility. The presence of an ecosystem leader is indispensable during this time. In the absence of a keystone organization, which brings together and connects the actors that will develop the technological innovation, the ecosystem faces the risk of disintegration already in the invention subphase. As a result, the keystone configures the ecosystem foundation during invention and gives it an opportunity to progress to the following phases of development. In addition to testing for technical viability, references of existing technologies in operation provide vitally needed confidence for the keystone firm to invest in developing the new innovation.

After technical feasibility assessment, the innovation is put to operation for the first time, thus commencing the start-up sub-phase. This period oversees the improvement of technological performance, which is typically curbed by technical bottlenecks that materialize during initial operation. Bottlenecks are seminal to ecosystem evolution as they form 'focusing devices' (Rosenberg, 1969), and it is through the resolution of bottlenecks (also referred to as 'reverse salients') that the technological system can deliver the promised value to the customer (Rosenberg, 1976; Hughes, 1983; Dedehayir and Mäkinen, 201I; Dedehayir and Mäkinen, 2008). Often the removal of bottlenecks to value creation involves reconfiguring the ecosystem. Adner (2012) proposes five levers of reconfiguration: (i) 'relocation' of actors; (ii) 'separation' of a single task into separate tasks to be undertaken by different actors; (iii) 'combination' of separate tasks to be undertaken by a single actor; (iv) 'addition' of new actors to undertake tasks that are currently absent but would benefit the ecosystem; and (v) 'subtraction' of existing actors and their tasks to benefit the ecosystem.

In our case study we witnessed the separation and addition strategies that overcame operation capacity bottlenecks, although these actions were not initiated by the keystone organization. In fact, we observed a shift in the ecosystem's locus from the invention sub-phase to the start-up subphase, as the intensity of ecosystem activities moved from inventing, developing, and testing the technology to operationalizing the technology in the field. This is an interesting finding, considering that the keystone is expected to take on a central role during this period. However, our case study shows that the ecosystem can still remain stable and progress toward value creation despite a moving centerof-gravity. Moreover, we observed that external forces played a significant role in not only creating bottlenecks but also promoting the resolution of bottlenecks. The ecosystem leaders, key actors, as well as external forces influencing ecosystem birth and expansion are summarized in Table I.

The start-up sub-phase ends with the removal of critical blockages, thus enabling the technology to perform as per design intent. The innovation ecosystem, in turn, enters the expansion phase, which denotes the period during which the technology is implemented in new areas or application fields. Our case study reveals several important characteristics of this life cycle phase. 


\section{Birth}

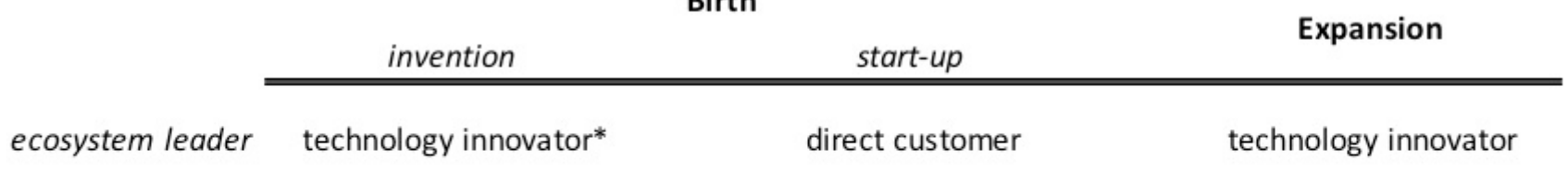

inventor

key actors

direct customer

research laboratories

technology innovator

specialized engineering companies

direct customers

universities

external forces

industry changes

government regulations

government regulations

*technology innovator is the firm commercializing the technology

Table I. Actors of the innovation ecosystem at birth and expansion phases.

Firstly, the expansion into new application territories requires patience and energy. The effort needed to expand the ecosystem is somewhat akin to crossing the 'chasm' that exists between the early adopter and the early majority adopter categories identified in the diffusion of innovation research (Moore, 1999; Rogers, 1995). In both the diffusion of an innovation and the expansion of the ecosystem, the challenge for the innovating firm(s) is to attract new customers who will commit to acquiring the technology. The adoption decision of these potential customers typically requires confidence in the new technology which they gain from references of already implemented and working models. From the supply side, the ecosystem can therefore speed up the expansion process by seeking a 'beachhead' (Moore, 1999), in other words a small group of adopters in the larger application realm, which subsequently act as reference for other adopters. In fact, our case study showed that a single entrepreneur in China served as the beachhead and reference for a number of further adoptions in the same market .

Connected with the above is the second observation that we make from the case study, which is the role of 'chance events' (Arthur, 2009) that lock the innovation ecosystem along a given path. For instance, after several unsuccessful attempts, the expansion of the ecosystem was initiated by a contact from an entrepreneur in China, an event that was not foreseen. We thirdly witness the vulnerability of the ecosystem to chance events sourced from outside of the ecosystem of actors. In particular, governments, regulatory bodies, industries, and institutions (referred to as the 'superstructure' in CoPS literature (Miller et al., 1995)) can trigger the change of course of ecosystem development. As our case study demonstrates, the influence of the superstructure is present in both the birth and expansion phases, and more importantly, the influences can be both negative and positive to the ecosystem's development. For instance, the copper industry halted ecosystem development in the invention sub-phase, while the Chinese government created a window of opportunity for ecosystem expansion through more stringent emission regulations. And fourthly, our case study underlined that in addition to the actions of actors internal and external to the innovation ecosystem, the expansion of the ecosystem is determined by processes internal to the keystone organization. As underlined in prior literature (Christensen, 1997), the addition of a new innovation into the product portfolio of the organization presents a point of punctuation, resulting in the emergence of bipartisan groups, one supporting investment into the new technology, while the other opposing this notion. Whether the new technology receives the necessary resources to allow for continued research and development, and also the green light for seeking new application realms is reliant on the internal dialogue between these opposing camps. Our case study shows that the ecosystem's expansion can indeed be blocked by this firm-centric process. 


\section{Conclusions}

We have demonstrated with a single case study how an ecosystem progresses through the early phases of its life cycle. More specifically, we identified two sub-phases in the birth phase, invention and start-up, which prepare the ecosystem to enter the expansion phase. From our case study, it appears that the initial customer should assume the role of ecosystem leader in order to reconfigure the ecosystem towards viable business. However, further research should be done in similar settings to dig deeper and provide more understanding of this type of development. In addition, further studies could shed more light on the role of the superstructure and its triggering nature - in other words, to identify whether these developments take place typically for CoPS ecosystems or whether similar windows of opportunity arise in other settings as well. We acknowledge the traditional case study research limitations. Our empirical work studied a single case in a particular setting and its selection was partly based on accessibility. Furthermore, the duration of our study was not sufficient to capture the ongoing nature of the ecosystem's expansion, which may reveal important sub-phases as we have also observed in the birth phase of the ecosystem. We believe that continued investigation of other CoPS ecosystem cases can identify repeating patterns, while comparative studies of other innovation ecosystem types, such as those producing high-volume products and services, can illuminate important aspects of ecosystem evolution in general.

\section{References}

ADNER, R. (20I2). The Wide Lens: A New Strategy for Innovation. Portfolio/Penguin, U.S.A.

ADNER, R., Kapoor, R. (2010). Value creation in innovation ecosystems: How the structure of technological interdependence affects firm performance in new technology generations. Strategic Management Journal, 3 I, 306-333. doi: 10.2139/ssrn. 1353582

ARTHUR,W. B. (2009). The Nature of Technology: What it is and how it Evolves. Penguin Books, Great Britain.

CHRISTENSEN, C. M. (1997). The innovator's dilemma: when new technologies cause great firms to fail. Harvard Business School Press, Boston, Massachusetts.

CUSUMANO, M. A., Gawer, A. (2002). The elements of platform leadership. MIT Sloan Management Review, Spring, $5 \mathrm{I}-58$.

DEDEHAYIR,O.,Nokelainen,T.,Mäkinen,S.J.(20I4).Disruptive innovations in Complex Product Systems industries: A case study. Journal of Engineering and Technology Management, 33, 174-192. doi: 10.1016/j.jengtecman.2014.06.002

DEDEHAYIR, O., Mäkinen, S. J. (20I I). Determining reverse salient types and evolutionary dynamics of technology systems with performance disparities. Technology Analysis \& Strategic Management, 23(10), 1095-III4. doi: I0.1080/09537325.20II.62I308

DEDEHAYIR, O., Mäkinen, S. J. (2008). Dynamics of reverse salience as technological performance gap: An empirical study of the personal computer technology system. Journal of Technology Management \& Innovation, 3(3), 55-66. doi: I0.4067/s07|8-27242008000I00006

HUGHES, T. P. (1983). Networks of Power: Electrification in Western Society, 1880-1930. The John Hopkins University Press, USA.

IANSITI, M., Levien, R. (2004). Strategy as ecology. Harvard Business Review, March, I-I0.

KOJO, I., Lahtinen, M., Miettinen, E. (2009). Flash converting Sustainable technology now and in the future. In International Peirce-Smith Converting Centennial, eds. J. Kapusta \& T. Warner, 383-395. 
MÄKINEN, S. J., Dedehayir, O. (2012). Business ecosystem evolution and strategic considerations: A literature review. 18th International ICE-Conference on Engineering, Technology, and Innovation, Munich, Germany, June 18-20. doi: I0.1 109/ice.2012.6297653

MILES, M. S., Huberman,A. M. (1994). Qualitative data analysis: an expanded sourcebook. Thousand Oaks, CA.

MILLER, R., Hobday, M., Leroux-Demers, T., Olleros, X. (1995). Innovation in complex system industries: The case of flight simulators. Industrial and Corporate Change, 4, 363400. doi: $10.1093 / \mathrm{icc} / 4.2 .363$

MOORE, G. A. (1999). Crossing the Chasm: Marketing and Selling High-Tech Products to Mainstream Customers. Harper Business, New York.

MOORE, J. F. (1993). Predators and prey: A new ecology of competition. Harvard Business Review, May-June, 75-86.

ROGERS, E. M. (1995). Diffusion of Innovations. The Free Press, New York.

ROSENBERG, N. (1976). Perspectives on Technology. Cambridge University Press, Cambridge.

ROSENBERG, N. (1969). The direction of technological change: inducement mechanisms and focusing devices. Economic Development and Cultural Change, 18, I-24. doi: $10.1086 / 450399$

SCHLESINGER, M. E., King, M. J., Sole, K. C., Davenport, W. G. (20I I). Extractive Metallurgy of Copper. 5th edn, Elsevier Ltd., Oxford, UK.

TIWANA, A., Konsynski, B., Bush, A. A. (2010). Platform evolution: Coevolution of platform architecture, governance, and environmental dynamics. Information Systems Research, 2I (4), 675-687. doi: 10.1287/isre. I 100.0323

YIN, R. K. (1994). Case study research: design and methods. 2nd edn, Sage Publications, Newbury Park, CA. 